\section{RASCH MODEL APPLICATION IN VALIDATING INSTRUMENT FOR KNOWLEDGE INTEGRATION IN SMALL MEDIUM ENTERPRISES}

\author{
Nur Ilyana Ismarau Tajuddin"1 ${ }^{*}$, Rusli Abdullah¹, Marzanah A. Jabar¹, Yusmadi Yah Jusoh'1, Nureize Arbaiy \\ ${ }^{1}$ Faculty of Computer Science and Information Technology, Universiti Putra Malaysia \\ ${ }^{2}$ Soft Computing and Data Mining Centre, Faculty of Computer Science and Information Technology, Universiti Tun Hussein \\ Onn, Johor, Malaysia \\ *Corresponding author email: ilyanaismarau90@gmail.com
}

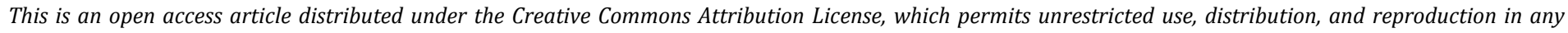
medium, provided the original work is properly cited.

\section{ARTICLE DETAILS}

Article history:

Received 07 August 2017

Accepted 11 October 2017

Available online 3 November 2017

\section{ABSTRACT}

This paper aims in analysing the application of Social Media to enhance the Knowledge Integra-tion (KI) by proposed of KI model for Small Medium Enterprises (SMEs) by using Rasch Model Application. An initial conceptual model has been constructed based on TOE framework (Tech-nology, Organization, Environment) which is including KI, Social Media, SMEs, Environment, and Service Quality Factors.

Keywords:

Rasch, Small Medium Enterprises

\section{INTRODUCTION}

Knowledge is acknowledged as a sustainable basis of competitive advantage for many organiza-tions possess [1]. Most Small Medium Enterprises (SMEs) have started to realize the importance of Knowledge Integration $(\mathrm{KI})$ in streamlining their operations and processes to improve organizational performance [2]. Due to this motivation, this paper aims in analysing the application of Social Media to enhance the Knowledge Integration (KI) by proposed of KI model for SMEs by using Rasch Model Application. An initial conceptual model has been constructed based on TOE framework (Technology, Organization, Environment) which is including $\mathrm{KI}$, Social Media, SMEs, Environment, and Service Quality Factors [3]. The data has been collected based on 31 employees from SMEs practitioners who are getting involved in KI with Social Media environ-ment. The result shows that person reliability is high (0.96) but item reliability is fair (0.70). Out-fit and infit mean square values are very much close to 1 , and Z- standardize value is within the expected range. Value for Point Measure Correlation (PMC) is more than 0 and positive value. So, there are no questions/ items which do not fit or not appropriately constructed. Unidimen-sionality shows that there is no visible secondary dimension. The initial model has been develop as a basic of the future model deployment of KI implement in SMEs.

\section{DESCRIPTION}

31 staff from Small Medium Enterprises (SMEs) in Malaysia participated in this pilot study. The pilot data were tabulated and analyzed using WinSteps. Rasch identified an extreme score which will later be excluded from further analysis. Person and Item summary statistics results and measures are shown in Figure 1 and Figure 2.

SUMMARY OF 31 MEASURED Persons

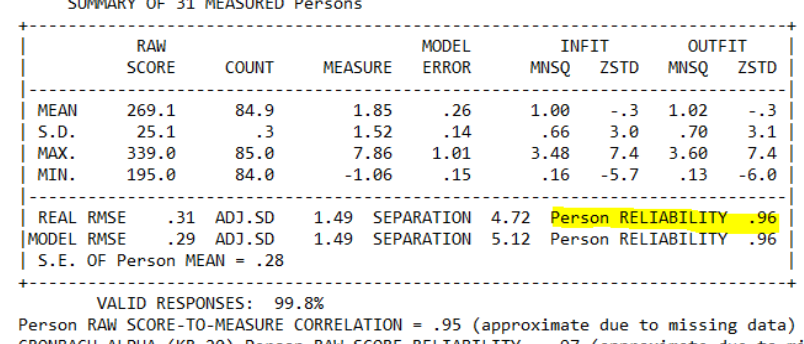

Person RAW SCORE-TO-MEASURE CORRELATION $=.95$ (approximate due to missing data)
CRONBACH ALPHA (KR-20) Person RAW SCORE RELIABILITY $=.97$ (approximate due to missing data)

Figure 1: Statistic Summary for person
SUMMARY OF 85 MEASURED Items

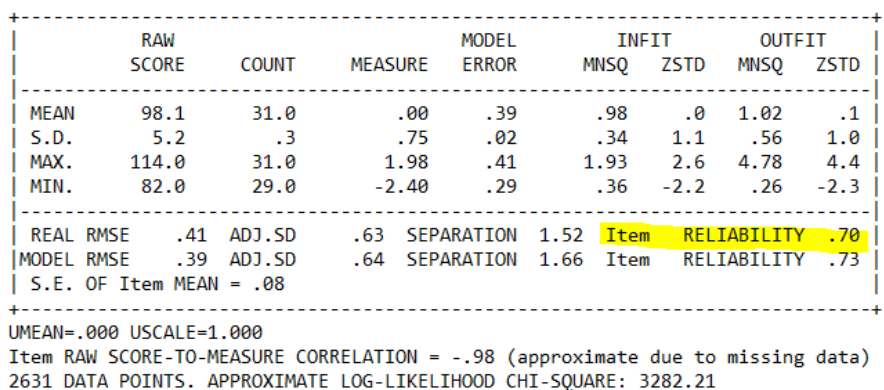

Figure 2: Statistic Summary for item

Figure 1 also shows statistics summary for person of which Cronbach alpha is 0.96 is quite high. Hence, it means that the responses are reliable for analysis. Individual Mean is $1.85 \operatorname{logit}$. In other words, the logit shows that respondents endorse most items. The spread of person respondent is 7.86$(-1.06)=8.92$. This is due to very erratic by one of the respondent. The person separation is 4.72 is quite good. In Rasch, person separation is used to classify people. Low person separation $(<2$, person reliability $<0.8)$ with a relevant person sample implies that the instrument may not be not sensitive enough to distinguish between high and low performers. Whereas, Figure 2 shows statistic summary for item reliability score of 0.70 is fair. This might be due to small sam-ple size being used for analysis. The spread of item is $1.98-(-2.40)=4.38$. The item separation is 1.52

As shown in Figure 3, the person map illustrates that the person at the top are most agree-able while person at the bottom are most disagreeable to endorse. This indicates tendency to en-dorse higher importance for the questionnaire items. Person P03 being the highest in Wright Map, have the tendency to easily endorse to most of the items, while P11 tends to rate lower which mean, she or he hardly agrees with all items. On the Item side as show in Figure 4, the item at the top are the most difficult question (item) and at the bottom are easiest item. The dis-tribution is quite closely bunched together, except for A1. This might be due to respondents may not understand the term 'structured format' used in the item. Therefore, this question will be re-vised for easier understanding. Almost all items are below person mean, except $\mathrm{H} 4$ and A7. This indicates overall agreeableness on the high importance of these factors. 


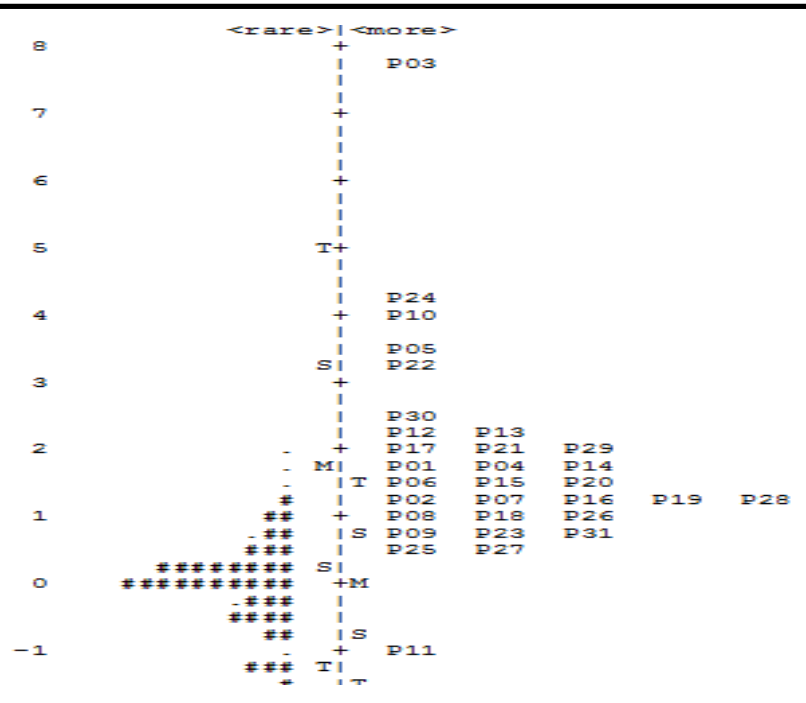

Figure 3: Item map of Person

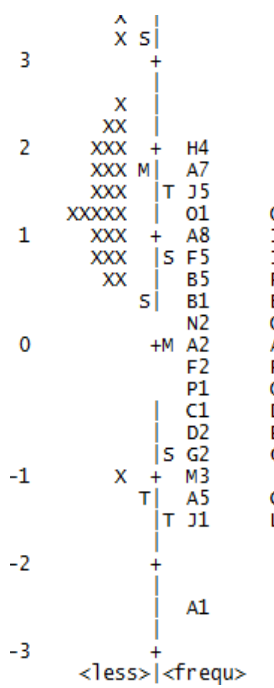

Figure 4: Person map of Item
Analysis obtain from Figure 5 shows value for Point Measure Correlation (PMC) is more than 0 and positive value. So, that there are no questions/ items which do not fit or not appropriately constructed. Therefore, no further action, such as checking or eliminating any questions should be taken.

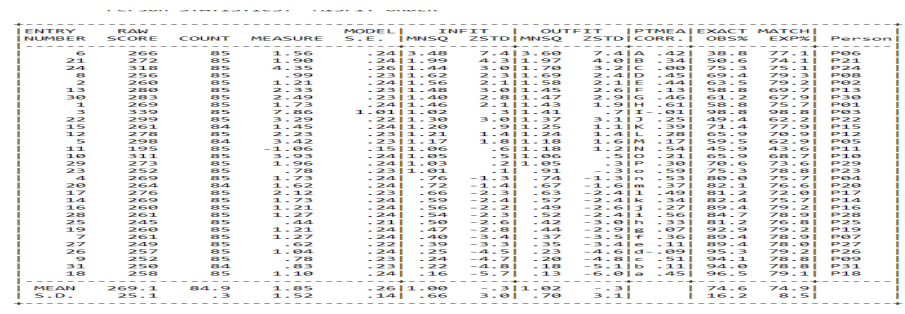

Figure 5: Item/Person Measure

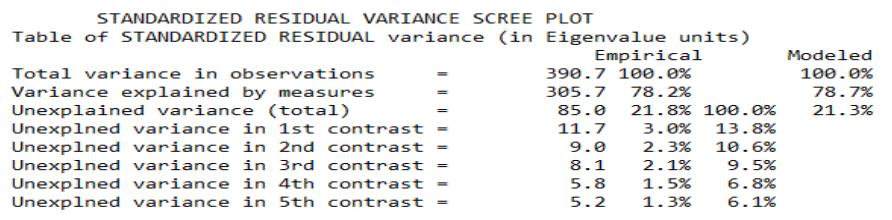

Figure 6: Item map of Person

\section{REFERENCES}

[1] Grant, R.M. 1996. Toward a knowledge-based theory of the firm. Strategic Management Journal,17 (S), 109- 122.

[2] Jeroen, K., Dorn, F., Aharon, H. 2006. Knowledge Integration by SMEsFramework. Knowledge Integration: The Practice of Knowledge Management in Small and Medium En-terprises. Eds. Jetter, Anotonie. Germany: Physica-Verlag Heidelberg.

[3] Angeles, R. 2013. 7G'S Enviromental Initiative through the Lens of Technology-Organizational-Enviroment (TOE). Framework Computer Technology and Application, 4, 39-68.

[4] Fisher, W. P. 2007. Rating Scale Instrument Quality Criteria. Rasch Measurement Transac-tions, 21, 1095. 